\title{
Rainfall thresholds for the possible occurrence of landslides in Italy
}

\author{
M. T. Brunetti ${ }^{1}$, S. Peruccacci ${ }^{1}$, M. Rossi ${ }^{1}$, S. Luciani ${ }^{2}$, D. Valigi ${ }^{2}$, and F. Guzzetti ${ }^{1}$ \\ ${ }^{1}$ Istituto di Ricerca per la Protezione Idrogeologica, Consiglio Nazionale delle Ricerche, via Madonna Alta 126, \\ 06128 Perugia, Italy \\ ${ }^{2}$ Dipartimento di Scienze della Terra, Università degli Studi di Perugia, piazza dell’Università 1, 06123 Perugia, Italy
}

Received: 22 January 2010 - Accepted: 28 February 2010 - Published: 11 March 2010

\begin{abstract}
In Italy, rainfall is the primary trigger of landslides that frequently cause fatalities and large economic damage. Using a variety of information sources, we have compiled a catalogue listing 753 rainfall events that have resulted in landslides in Italy. For each event in the catalogue, the exact or approximate location of the landslide and the time or period of initiation of the slope failure is known, together with information on the rainfall duration $D$, and the rainfall mean intensity $I$, that have resulted in the slope failure. The catalogue represents the single largest collection of information on rainfall-induced landslides in Italy, and was exploited to determine the minimum rainfall conditions necessary for landslide occurrence in Italy, and in the Abruzzo Region, central Italy. For the purpose, new national rainfall thresholds for Italy and new regional rainfall thresholds for the Abruzzo Region were established, using two independent statistical methods, including a Bayesian inference method and a new Frequentist approach. The two methods proved complementary, with the Bayesian method more suited to analyze small data sets, and the Frequentist method performing better when applied to large data sets. The new regional thresholds for the Abruzzo Region are lower than the new national thresholds for Italy, and lower than the regional thresholds proposed in the literature for the Piedmont and Lombardy Regions in northern Italy, and for the Campania Region in southern Italy. This is important, because it shows that landslides in Italy can be triggered by less severe rainfall conditions than previously recognized. The Frequentist method experimented in this work allows for the definition of multiple minimum rainfall thresholds, each based on a different exceedance probability level. This makes the thresholds suited for the design of probabilistic schemes for the prediction of rainfall-induced landslides. A scheme based on four probabilistic thresholds is proposed. The four thresh-
\end{abstract}

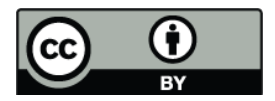

Correspondence to: $\mathrm{M}$. T. Brunetti (mariateresa.brunetti@irpi.cnr.it) olds separate five fields, each characterized by different rainfall intensity-duration conditions, and corresponding different probability of possible landslide occurrence. The scheme can be implemented in landslide warning systems that operate on rainfall thresholds, and on precipitation measurements or forecasts.

\section{Introduction}

Landslides are frequent and widespread geomorphological phenomena in Italy (Guzzetti et al., 1994; Guzzetti and Tonelli, 2004). In this Country, a nationwide investigation completed by the Italian National Geological Survey has identified approximately $5 \times 10^{5}$ landslides, an average of 1.6 slope failures per square kilometre (Trigila, 2007). Independent investigations indicate that this is a lower estimate (e.g., Servizio Geologico, Sismico dei Suoli, 1999; Guzzetti et al., 2008). Damage caused by landslides is severe in Italy. In the 60-year period 1950-2009, at least 6349 persons were killed, went missing, or were injured by slope failures in Italy, with an average of 16 harmful events per year. This is evidence of the considerable risk posed by landslides to the population of Italy (Guzzetti, 2000; Guzzetti et al., 2005a, b; Salvati et al., 2003, 2010).

In Italy, landslides are caused primarily by rainfall. Depending on meteorological and physiographical conditions, individual rainfall events can cause slope failures in areas of limited extent or in large regions. In the period 2-6 November 1994, prolonged rainfall triggered several thousands shallow and deep-seated landslides in an area of thousands of square kilometres in northwestern Italy (Regione Piemonte, 1998; Luino, 2005). On 1 October 2009, a high intensity rainstorm in the Messina area, Sicily, triggered more than 500 shallow landslides in an area of less than $60 \mathrm{~km}^{2}$. Both events caused casualties, and severe economic losses. These prototype events illustrate the need for methods to predict rainfall-induced landslides in Italy.

Published by Copernicus Publications on behalf of the European Geosciences Union. 
In the literature, two approaches have been proposed to evaluate the dependence of landslide occurrence (or lack of occurrence) on rainfall measurements. The first approach is based on process-based models (Montgomery and Dietrich, 1994; Wilson and Wieckzorek, 1995; Wu and Sidle, 1995; Iverson, 2000; Crosta and Frattini, 2003), and the second approach relies on the definition of empirical thresholds (Caine, 1980; Reichenbach et al., 1998; Corominas, 2000; Aleotti, 2004; Wieczorek and Glade, 2005; Guzzetti et al., 2007, 2008). Process-based models rely upon the understanding of the physical laws controlling slope instability, and attempt to extend spatially the simplified stability models widely adopted in geotechnical engineering. Stability conditions are evaluated chiefly by means of a static stability model where the local equilibrium along a potential slip surface is considered. Most commonly, the slip surface is assumed planar, of fixed depth, and parallel to the topographic surface. Values for the pore fluid pressure are assumed, or obtained by adopting more or less complex rainfall infiltration models.

An empirical threshold defines the rainfall, soil moisture, or hydrological conditions that, when reached or exceeded, are likely to trigger landslides (Reichenbach et al., 1998). Rainfall thresholds for the possible occurrence of landslides are defined through the statistical analysis of past rainfall events that have resulted in slope failures, and can be classified based on the geographical extent for which they are determined (i.e., global, national, regional, or local thresholds), and the type of rainfall information used to establish the threshold (Guzzetti et al., 2007, 2008).

In this work, we exploit a catalogue of rainfall events that have resulted in landslides in Italy to define new thresholds for the possible occurrence of rainfall-induced landslides, in Italy and in the Abruzzo Region, central Italy. We begin by illustrating the catalogue of rainfall events that have resulted in landslides in Italy (Sect. 2). Next, we describe two statistical methods for the definition of objective rainfall thresholds, including a Bayesian inference method and a new method based on a Frequentist probabilistic approach (Sect. 3). Then, we apply the two methods to the catalogue to determine new intensity-duration (ID) thresholds for possible landslide occurrence in Italy and in the Abruzzo Region, central Italy (Sect. 4), and we compare the new thresholds to similar thresholds proposed for Italy (Sect. 5). We conclude by proposing a probabilistic scheme based on multiple rainfall thresholds for the forecast of possible landslide occurrence.

\section{Catalogue of rainfall induced landslides in Italy}

Searching the scientific and technical literature, Guzzetti et al. (2007) compiled a first catalogue of 853 rainfall events that resulted, or did not result, in landslides of different types in central and southern Europe, including 776 events in Italy. Through an extended literature search, Guzzetti et al. (2008) expanded the catalogue to comprise 2626 rainfall events globally, including 855 events in Italy, that have resulted in shallow landslides and debris flows. The worldwide catalogue was further expanded to include 6962 rainfall events that have (or have not) resulted in landslides of all types.

For each rainfall event, the information collected and stored in the worldwide catalogue includes: (i) the precise or approximate location of the area affected by the rainfall and the landslides, (ii) the precise or approximate time, date, or period of the failures, (iii) the rainfall conditions that resulted (or did not result) in slope failures, including the total event rainfall, the rainfall duration, the mean rainfall intensity, and the antecedent rainfall for different periods, (iv) the landslide type, according to Cruden and Varnes (1996), (v) the number of the triggered landslides, in 5 classes, (vi) a generic description of the main rock types (e.g., sedimentary, volcanic, intrusive, metamorphic rocks) obtained from synoptic scale geological maps, and (vii) general climatic information, including a class of the Köppen climate classification system (Köppen, 1936; Trewartha, 1968), the mean annual precipitation (MAP), the average number of rainy days (RDs), and the Rainy-Day normal (RDN, Wilson and Jayko, 1997). Due to lack of standards for reporting rainfall conditions and geomorphological information, inconsistency exists in the global catalogue, and not all the information is available for all the events listed in the catalogue. A description of the main sources of information, of the problems encountered, and the methods adopted to compile the information, and of the completeness of the catalogue, was given by Guzzetti et al. (2007, 2008).

For this work, we have re-examined the literature reporting information on rainfall events that have resulted in slope instability in Italy. Examination allowed us to identify a few duplicate events, and events for which the rainfall or landslide information was not considered reliable or sufficiently documented. These events were excluded from the catalogue. Further inspection of the catalogue allowed singling out landslide events that were not caused solely (or certainly) by rainfall, including landslides related to snowmelt events. These events were also excluded from the catalogue. At the end of the review process, we obtained a catalogue of 587 rainfall events in Italy that have resulted in landslides of different types, in the 168-year period 1841-2008. In this catalogue, the percentage of events for which the year is known is $54.6 \%$. For this subset of dated events, 15 (4.7\%) occurred before 1950, and $221(68.8 \%)$ occurred in the 34year period 1975-2008.

Analysis of the geographical distribution of the rainfall and landslide events listed in the catalogue revealed a distinct geographical bias, with the majority of the events in northern Italy $(85.0 \%)$, chiefly in the Alps mountain range, and the remaining events almost equally distributed in central $(7.7 \%)$ and southern $(7.3 \%)$ Italy. The catalogue did not list rainfall events with landslides in Sicily and in Sardinia, although 
rainfall-induced slope failures are known to occur in these two regions of southern Italy (Guzzetti et al., 1994; Guzzetti and Tonelli, 2004).

In an attempt to collect additional information on rainfall events that have resulted in landslides in Italy, and chiefly in central and southern Italy, we searched new sources of information including: (i) newspapers, with emphasis on those available on line, (ii) event reports and anecdotal information provided by the Italian national Department for Civil Protection, and (iii) recent publications and other technical reports. The search was limited to the period between January 2002 and June 2009. For this period, a database of rainfall measurements for 1950 rain gauges in Italy, corresponding to an average density of one rain gauge every $\sim 150 \mathrm{~km}^{2}$, was available to us. In the database, rainfall measurements were cumulated every $10,15,30$, or $60 \mathrm{~min}$, allowing for a detailed reconstruction of a rainfall event, in terms of rainfall duration $D$, and rainfall mean intensity $I$.

We obtained information on landslide occurrence chiefly from newspapers, and subordinately from the other sources. The information was used to locate geographically (i.e., "where" a landslide occurred) and temporally (i.e., "when" it occurred) individual or multiple landslides triggered by the same rainfall event. When the exact or approximate location, and the (known or inferred) time or period of initiation of the failure(s) were identified, the database of rainfall measurements was searched to determine the rainfall duration $D$, and the rainfall mean intensity $I$ that have resulted in slope instability. In general, three to four rain gauges were considered, and the most representative measuring station was selected. Representativeness of a rain gauge was decided based on the geographical distance to the landslide (or landslide area), the elevation of the rain gauge compared to the elevation of the landslide, and the location of a rain gauge with respect to the local topographical and morphological setting. In general, a rain gauge was select to be the closest to the landslide (or landslide area) in the pool of rain gauges located in the same valley. In other cases, for the selection of the representative rain gauge, elevation was considered more important than geographical distance to the landslide.

When an appropriate rain gauge was identified, the rainfall duration $D$ was determined measuring the time between the moment, or period, of initiation of the failure(s) (rainfall ending time) and the time when the rainfall event started (rainfall starting time). For failures for which the time and date of occurrence were known, the rainfall ending time was taken to coincide with the time of the last rainfall measurement of the hour when the landslide occurred. Similarly, for failures for which only the date of occurrence was known, the rainfall ending time was taken to coincide with the time of the last rainfall measurement of the day when the landslide occurred. For some of the rainfall events, precise identification of the starting time was problematic. We considered a minimum period without rain to separate two rainfall events. To account for different meteorological regimes that may result in landslides in Italy, a different minimum period was selected for the different seasons: a two-day period without rainfall was selected for late spring and summer (May-September), and a four-day period without rainfall was selected for the other seasons (October-April). When the duration of the event was established, the corresponding rainfall mean intensity $I$ (in $\mathrm{mm} \mathrm{h}^{-1}$ ) was calculated dividing the cumulated (total) rainfall in the considered period (in $\mathrm{mm}$ ) by the length of the rainfall period (in hours). Using this method, the rainfall mean intensity for the event was determined (Guzzetti et al., 2007, 2008).

We acknowledge that the identification of a rainfall event, and the definition of the rainfall duration $D$ and rainfall mean intensity $I$ for the event, were somewhat heuristic, and for some of the events guided by inference and by the experience of the investigator. For a few uncertain events, multiple investigators analysed and discussed the same information, until a consensus was reached. This has introduced uncertainty in the catalogue. Quantification of the uncertainty was not possible.

For some of the landslides for which information was available from the sources, accurate or even approximate reconstruction of the corresponding rainfall event was especially uncertain, impractical, or impossible. These events ( $\sim 30 \%$ of the total number of investigated events) were not included in the catalogue. Reasons for discarding an event were manifold, including the fact that: (i) landslides were not induced by rainfall (or exclusively by rainfall, e.g., they were caused by rain-on-snow or by snowmelt; Jakob and Weatherly, 2003; Cardinali et al., 2000), and consequently the relationship between landslide occurrence and rainfall amount (or intensity) was weak or inexistent, (ii) the area where landslides were reported was affected by wildfires recently, a condition known to alter the amount of rainfall that can initiate slope failures (Cannon and Gartner, 2005), (iii) geographical location of the landslide was not possible or exceedingly imprecise, and (iv) rain gauges were not present in the area where a landslide was reported, or rainfall measurements were not available for the event that triggered the landslide.

Joint analysis of the landslide and rainfall records allowed identifying 166 new rainfall events that have triggered landslides in Italy in the period 2002-2009, including 77 events in the Abruzzo Region, central Italy. The large proportion of new events in the Abruzzo Region is the result of a specific effort in this Region following the 6 April 2009 earthquake (Brunetti et al., 2009). The new events were added to the national catalogue for Italy. Collectively, the catalogue of rainfall events with landslides in Italy lists 753 events. Most of the events $(70.3 \%)$ are located in northern Italy, $19.8 \%$ in central Italy, and $9.9 \%$ in southern Italy. Thus, a geographical bias still exists in the catalogue. Figure 1 shows maps portraying the abundance of the rainfall events that triggered landslides in the 20 Italian Regions (Fig. 1a) and the distribution of 1950 rain gauges (Fig. 1b). 

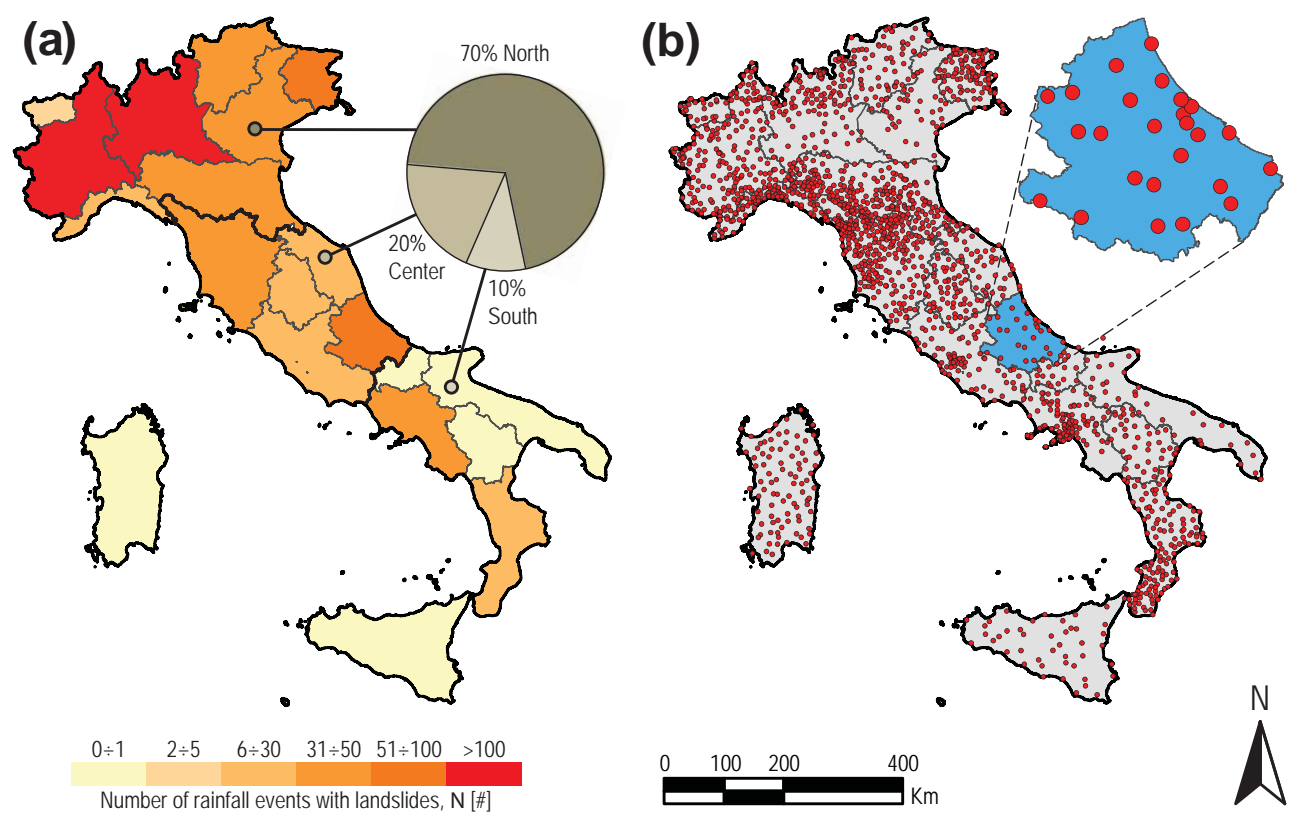

Fig. 1. Landslide and rainfall information in Italy. (a) Regional abundance of 753 rainfall events that have resulted in landslides listed in the catalogue in the period 1841-2009. (b) Map showing the location of 1950 rain gauges in Italy, including 25 rain gauges in the Abruzzo Region, central Italy (light blue area).

\section{Methods for the objective definition of rainfall thresholds}

Review of the literature (Guzzetti et al., 2007, 2008) has revealed that for most of the published empirical rainfall thresholds for the possible initiation of landslides, the mathematical or statistical criteria used to determine the thresholds are inadequately specified, or poorly constrained. As discussed by Guzzetti et al. (2007, 2008), there is scope for the definition and validation of methods for the calculation of objective (i.e., reproducible) rainfall thresholds for the possible occurrence of rainfall-induced landslides. In this section, we describe two statistical methods for the definition of objective rainfall intensity-duration (ID) thresholds. The first method is based on Bayesian inference, and the second method adopts a Frequentist approach. Both methods assume a threshold curve of the form:

$I=\alpha D^{-\beta}$

i.e., a simple power law, where $I$ is the rainfall mean intensity (in $\mathrm{mm} \mathrm{hr}^{-1}$ ), $D$ is the duration of the rainfall event (in hr), $\alpha$ is a scaling constant (the intercept), and $\beta$ is the shape parameter that defines the slope of the power law curve. The two methods differ in the way the scale $\alpha$ and the shape $\beta$ for the threshold curve are determined. It is worth pointing out that selection of a power law as the threshold curve is independent of any physical (i.e., geological, geomorphological, hydrological, meteorological) criteria (Reichenbach et al., 1998), and that different forms for the threshold curve can be selected (Crosta and Frattini, 2001).

\subsection{Bayesian inference method}

Guzzetti et al. (2007) were first to propose the Bayesian inference method, and have used it to determine minimum-ID and normalized-ID thresholds for the initiation of landslides in central and southern Europe. Guzzetti et al. (2008) adopted the same inference method to establish global, minimum-ID and normalized-ID thresholds for the possible initiation of shallow landslides and debris flows.

In this method, a probability approach is used to obtain estimates for the scale $\alpha$ (the intercept) and the shape $\beta$ (the slope) of the power law curve representing the threshold, based on a set of rainfall intensity $(I)$ and duration $(D)$ conditions that have resulted in landslides. This is obtained by defining a Bernoulli probability $\left(0 \leq p \leq 1, p \in \mathbb{R}^{+}\right)$of a data point occurring at a given value of rainfall intensity $I$ and duration $D$,

$P(I, D) \approx \operatorname{dbern}[\mu(I, D)]$

with:

$\mu(I, D)=\{(1-\delta) \Theta[z(I, D)]+\delta\} \exp [-\eta|z(I, D)|]$

In Eq. (3), $\Theta$ is the Heaviside step function (Abramowitz and Stegun, 1972), and $\delta$ and $\eta$ together represent the spread of data points in the $D-I$ space and across the inferred threshold along $z(I, D)=1-\alpha D^{-\beta} / I$. In the model, experimentation is required to define acceptable tolerance values $\delta$ and $\eta$, most commonly $\delta=0.5$ and $\eta=0.1$, and suitable ranges 
for the prior probability distributions for $\alpha$ and $\beta$, commonly $1 / \alpha \sim$ dunif $[0.001,100]$ and $\beta \sim$ dunif $[0.1,2]$. Finally, the estimates of $\alpha$ and $\beta$, obtained through Bayesian inference of their posterior probability distributions given the model and the empirical data, are used to define the minimum-ID threshold curve. To perform the Bayesian inference, we used WinBUGS, release 1.4.1 (Lunn et al., 2000, http://www.mrc-bsu.cam.ac.uk/bugs/).

\subsection{Frequentist method}

The second method adopts a Frequentist approach to determine the intercept $\alpha$ and the slope $\beta$ of the power law curve selected to represent the rainfall threshold. The method is based on a frequency analysis of the empirical rainfall conditions that have resulted in known landslides. To account for problems associated with the fitting of data spanning multiple orders of magnitude (e.g., the least square minimization criteria may not work), the empirical data are first logtransformed. The empirical rainfall data are plotted in a single graph (Fig. 2a), and the distribution of the rainfall conditions, $\log (I)$ vs. $\log (D)$, that have resulted in landslides is fitted (least square method) with a linear equation of the type $\log (I)=\log (\alpha)-\beta \log (D)$ (continuous purple line in Fig. 2a), which is entirely equivalent to the power law of Eq. (1) in linear coordinates.

Next, for each rainfall event, the difference $\delta(D)$ between the logarithm of the event intensity $\log [I(D)]$ and the corresponding intensity value of the fit $\log \left[I_{\mathrm{f}}(D)\right]$ is calculated, $\delta(D)=\log [I(D)]-\log \left[I_{\mathrm{f}}(D)\right]$. Then, the probability density function pdf of the distribution of $\delta(D)$ is determined through Kernel Density Estimation (Silverman, 1986; Scott, 1992; Venables and Ripley; 2002), and the result fitted (least square method) with a Gaussian function,

$f(x)=a \exp \left(-\frac{(x-b)^{2}}{2 c^{2}}\right)$,

where $a>0, c>0$, and $a, b, c \in \mathbb{R}$. Figure $2 b$ portrays the Gaussian fit (solid black line) of the pdf (dashed blue line) for the 753 empirical data points $(D, I)$ shown in Fig. 2a.

Lastly, thresholds corresponding to different exceedance probabilities are defined, based on the modeled (fitted) distribution of $\delta(D)$. As an example, Fig. 2c portrays the 5\% threshold as a red solid line. The distance $\delta^{*}$ between the red line and the mean of the distribution (solid grey line) is used to calculate the intercept of the $5 \%$ threshold curve, i.e. the $\log (I)$ value corresponding to $\log (D)=0(D=1 \mathrm{~h})$ in Fig. 2a. The $5 \%$ rainfall threshold $\mathrm{T}_{5}$ is the curve parallel to the best-fit line $\mathrm{T}_{50}$ (slope $=\beta$ ), with intercept $\alpha_{5}=\alpha_{50}-\delta^{*}$. For the 5\% threshold, assuming the catalogue of rainfall events is sufficiently complete and representative for Italy, we can state that the probability of experiencing landslides triggered by rainfall below this threshold is less than $5 \%$. The method can be used to determine thresholds for any exceedance probability level. Calculation of the rainfall thresholds using the
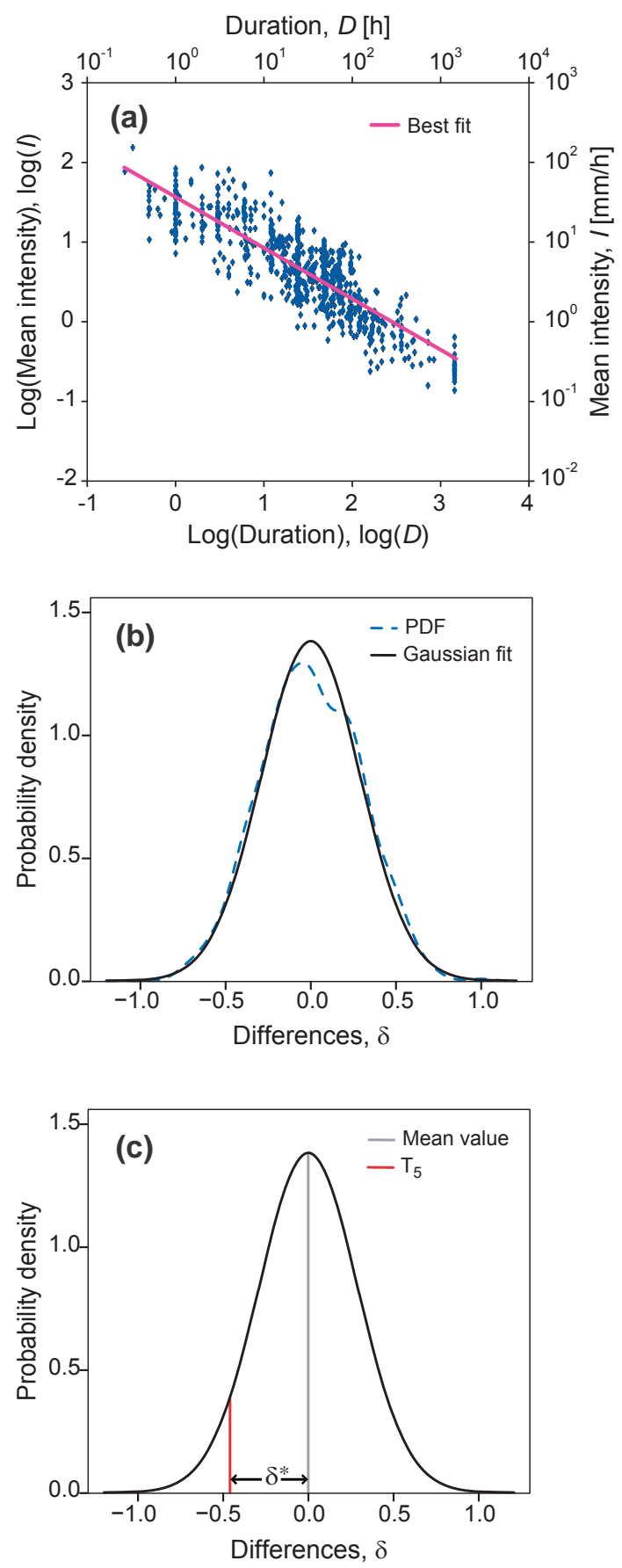

Fig. 2. (a) 753 rainfall events that have resulted in landslides in Italy, in the period 1841-2009, for which the rainfall duration $D$ (in $\mathrm{hr}$ ) and the rainfall mean intensity $I$ (in $\mathrm{mm} \mathrm{h}^{-1}$ ) are known. Error bars on the rainfall mean intensity $I$ show systematic error, assumed fixed and equal to $10 \%$. Errors on the rainfall duration $D$ were considered negligible and are not shown. The purple line is a fit (least square method) of the empirical rainfall $(D, I)$ conditions. (b) Kernel Density Estimation of the differences $\delta(D)$ (in blue), fitted with a Gaussian function (in black), for the distribution of the empirical data points $(D, I)$. (c) Graphical representation of the threshold corresponding to the $5 \%$ exceedance probability $\left(\mathrm{T}_{5}\right)$. 
Frequentist method was performed using the R open-source software for advanced statistical computing and graphics, release 2.6.2 (http://www.r-project.org/).

\section{New thresholds for landslide occurrence in Italy and in the Abruzzo Region}

We exploited the catalogue of 753 rainfall events that have resulted in landslides in Italy in the 169-year period 18412009, including 77 events in the Abruzzo Region between 2002 and 2009, to determine new rainfall thresholds for the possible occurrence of slope failures in Italy, and in the Abruzzo Region. To determine the thresholds, we adopted the Bayesian inference method (Sect. 3.1) and the new Frequentist method (Sect. 3.2). Figure 3a shows the distribution of the 753 rainfall conditions $(D, I)$ that have resulted in landslides of all types in Italy (blue dots). Error bars on the mean intensity $I$ represent the systematic error, assumed to be fixed and equal to $10 \%$. Errors on the duration $D$ were considered negligible, and are not shown. In our catalogue, rainfall events that have resulted in slope instabilities in Italy cover the range of duration $0.27 \mathrm{~h}<D<1440 \mathrm{~h}$ (i.e., from 15 min to 60 days), with the majority of the events in the range $12 \mathrm{~h}<D<120 \mathrm{~h}$, and span the range of rainfall mean intensity $0.15 \mathrm{~mm} \mathrm{hr}^{-1}<I<150 \mathrm{~mm} \mathrm{hr}^{-1}$, with the majority of the events in the range $0.5 \mathrm{~mm} \mathrm{hr}^{-1}<I<10 \mathrm{~mm} \mathrm{hr}^{-1}$.

Figure $3 \mathrm{a}$ also shows three national minimum-ID thresholds obtained by adopting the Bayesian $\left(\mathrm{T}_{\mathrm{B}}\right.$, green line) and the Frequentist methods. For the Frequentist method two threshold lines are shown: (i) a lower threshold corresponding to the $1 \%$ exceedance probability $\left(\mathrm{T}_{1}\right.$, light blue line), and (ii) a higher threshold corresponding to the 5\% exceedance probability $\left(T_{5}\right.$, red line). Note that both the $T_{1}$ and $\mathrm{T}_{5}$ thresholds are minimum-ID thresholds. The difference between the two thresholds is that one percent ( 7 to 8 data points) of the 753 data points shown in Fig. 3a are expected to be below the $\mathrm{T}_{1}$ (light blue) threshold, and five percent (37 to 38 data points) of the 753 data points are expected to be below the $\mathrm{T}_{5}$ (red) threshold. Inspection of Fig. 3a reveals that 7 data points are below the $T_{1}$ threshold, and 32 data points are below the $T_{5}$ threshold. For comparison, 11 data points are found below the Bayesian $\mathrm{T}_{B}$ (green) threshold.

Inspection of Fig. 3a and Table 1 indicates that the $T_{B}$ (Bayesian) and the $\mathrm{T}_{1}$ (Frequentist) national thresholds are similar. The rainfall mean intensity $I$ for a duration $D$ of one hour is $7.2 \mathrm{~mm} \mathrm{hr}^{-1}$ for $\mathrm{T}_{\mathrm{B}}$ and $7.7 \mathrm{~mm} \mathrm{hr}^{-1}$ for $\mathrm{T}_{1}$. For a duration $D$ of $24 \mathrm{~h}$ (one day), $I$ is $1.0 \mathrm{~mm} \mathrm{hr}^{-1}$ for $\mathrm{T}_{1}$ and $1.2 \mathrm{~mm} \mathrm{hr}^{-1}$ for $\mathrm{T}_{\mathrm{B}}$. The Bayesian threshold is lowest (i.e., most conservative) for very short duration events $(D \lesssim 2 \mathrm{~h})$. For longer events, the $\mathrm{T}_{1}$ Frequentist threshold is lowest i.e., more conservative. For $D \gtrsim 300 \mathrm{~h}(\sim 12$ days), the Bayesian threshold is the less conservative, being higher than the $\mathrm{T}_{5}$ Frequentist threshold. The $\mathrm{T}_{1}$ and $\mathrm{T}_{5}$ thresholds are steeper $(\beta=0.64)$ than the $\mathrm{T}_{\mathrm{B}}(\beta=0.55)$ threshold, indicating that for
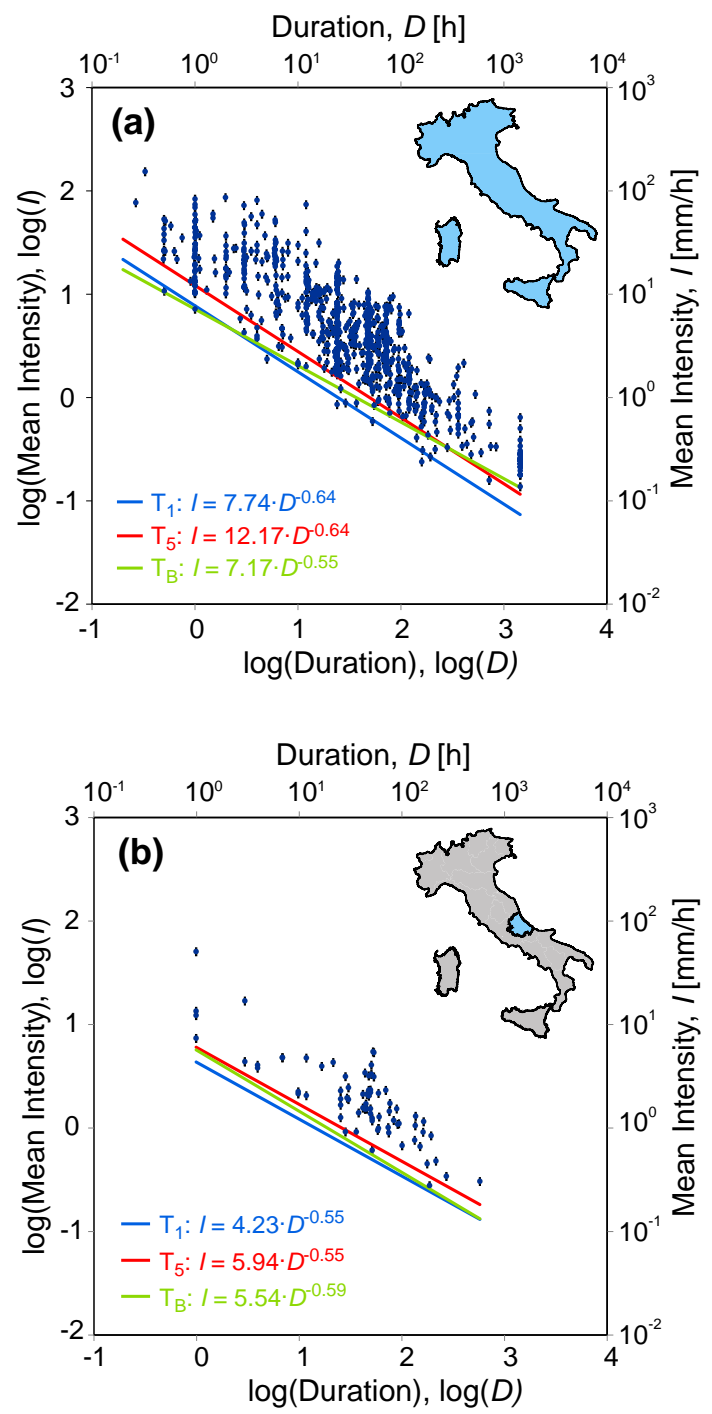

Fig. 3. Rainfall thresholds obtained using the Bayesian $\left(T_{B}\right.$, green line) and the Frequentist (light blue line is the $1 \%$ threshold, $\mathrm{T}_{1}$; red line is the $5 \%$ threshold $\mathrm{T}_{5}$ ) methods. Error bars on the rainfall mean intensity $I$ show systematic error, assumed fixed and equal to $10 \%$. Errors on the rainfall duration $D$ were considered negligible and are not shown. (a) Threshold curves for Italy. (b) Threshold curves for the Abruzzo Region, central Italy.

the Frequentist thresholds rainfall duration is more important than the rainfall mean intensity in discriminating between rainfall conditions that may or may not result in slope failures, compared to the Bayesian threshold (Guzzetti et al., 2008).

Figure $3 b$ shows the distribution of 77 rainfall conditions $(D, I)$ that have resulted in landslides in the Abruzzo Region, central Italy, in the period 2002-2009 (blue dots). Three regional, minimum-ID thresholds are also shown, which were obtained by adopting the Bayesian $\left(T_{B}\right.$, green line) and the Frequentist $\left(T_{1}\right.$, light blue line, 
Table 1. Rainfall ID thresholds for the possible initiation of landslides in Italy. Extent: G, global threshold; N, (Italian) national threshold; $\mathrm{R}$, regional threshold; L, local threshold. Area: the area where the threshold was defined. Type: landslide type, A, all types; D, debris flow; $\mathrm{S}$, soil slip; Sh, shallow landslide. Equation: $D$, rainfall duration in hours; $I$, rainfall mean intensity in $\mathrm{mm} \mathrm{h}^{-1}$. Range: range of validity for the threshold; Error: for the new thresholds defined in this work, standard errors associated with the estimation of the intercept $\alpha$ and the slope $\beta$ of the threshold curve. Source: 1-6, this work; 7, Caine (1980); 8, Innes (1983); 9, Jibson (1989); 10, Clarizia et al. (1996); 11, Crosta and Frattini (2001); 12, Cannon and Gartner (2005); 13-16, Guzzetti et al. (2008); 17-19, Guzzetti et al. (2007); 20, Ceriani et al. (1994) in Bacchini and Zannoni (2003); 21, Calcaterra et al. (2000); 22, Aleotti (2004); 23, Cancelli and Nova (1985); 24-29, Bolley and Olliaro (1999); 30, Marchi et al. (2002); 31, Floris et al. (2004); 32-35, Giannecchini (2005). See also Fig. 4.

\begin{tabular}{|c|c|c|c|c|c|c|}
\hline$\#$ & Extent & Area & Type & Equation & Range & Error \\
\hline 1 & $\mathrm{~N}$ & Italy & A & $I=7.74 \times D^{-0.64}$ & $0.2<D<1440$ & $\delta \alpha=0.41, \delta \beta=0.01$ \\
\hline 2 & $\mathrm{~N}$ & Italy & A & $I=12.17 \times D^{-0.64}$ & $0.2<D<1440$ & $\delta \alpha=0.65, \delta \beta=0.01$ \\
\hline 3 & $\mathrm{~N}$ & Italy & A & $I=7.17 \times D^{-0.55}$ & $0.2<D<1440$ & $\delta \alpha=0.01, \delta \beta=\sim 0$ \\
\hline 4 & $\mathrm{R}$ & Abruzzo, central Italy & A & $I=4.23 \times D^{-0.55}$ & $1<D<600$ & $\delta \alpha=0.69, \delta \beta=0.04$ \\
\hline 5 & $\mathrm{R}$ & Abruzzo, central Italy & $\mathrm{A}$ & $I=5.94 \times D^{-0.55}$ & $1<D<600$ & $\delta \alpha=0.97, \delta \beta=0.04$ \\
\hline 6 & $\mathrm{R}$ & Abruzzo, central Italy & A & $I=5.54 \times D^{-0.59}$ & $1<D<600$ & $\delta \alpha=0.07, \delta \beta=\sim 0$ \\
\hline 7 & G & World & Sh, D & $I=14.82 \times D^{-0.39}$ & $0.167<D<500$ & \\
\hline 8 & $\mathrm{G}$ & World & $\mathrm{D}$ & $I=4.93 \times D^{-0.50}$ & $0.1<D<100$ & \\
\hline 9 & $\mathrm{G}$ & World & $\mathrm{D}$ & $I=30.53 \times D^{-0.57}$ & $0.5<D<12$ & \\
\hline 10 & $\mathrm{G}$ & World & $\mathrm{S}$ & $I=10.00 \times D^{-0.77}$ & $0.1<D<1000$ & \\
\hline 11 & $\mathrm{G}$ & World & $\mathrm{Sh}$ & $I=0.48+7.20 \times D^{-1.00}$ & $0.1<D<1000$ & \\
\hline 12 & G & World & $\mathrm{D}$ & $I=7.00 \times D^{-0.60}$ & $0.1<D<3$ & \\
\hline 13 & $\mathrm{G}$ & World & Sh, D & $I=2.20 \times D^{-0.44}$ & $0.1<D<1000$ & \\
\hline 14 & $\mathrm{G}$ & World & Sh, D & $I=4.81 \times D^{-0.49}$ & $0.1<D<1000$ & \\
\hline 15 & $\mathrm{G}$ & World & Sh, D & $I=3.57 \times D^{-0.41}$ & $0.1<D<1000$ & \\
\hline 16 & $\mathrm{G}$ & World & Sh, D & $I=8.70 \times D^{-0.66}$ & $0.1<D<1000$ & \\
\hline 17 & $\mathrm{~N}$ & CADSES & A & $I=9.40 \times D^{-0.56}$ & $0.1<D<4000$ & \\
\hline 18 & $\mathrm{~N}$ & CADSES & A & $I=15.56 \times D^{-0.70}$ & $0.1<D<4000$ & \\
\hline 19 & $\mathrm{~N}$ & CADSES & A & $I=7.56 \times D^{-0.48}$ & $0.1<D<4000$ & \\
\hline 20 & $\mathrm{R}$ & Lombardy, northern Italy & A & $I=20.10 \times D^{-0.55}$ & $1<D<1000$ & \\
\hline 21 & $\mathrm{R}$ & Campania, southern Italy & A & $I=28.10 \times D^{-0.74}$ & $1<D<600$ & \\
\hline 22 & $\mathrm{R}$ & Piedmont, NW Italy & $\mathrm{Sh}$ & $I=19.00 \times D^{-0.50}$ & $4<D<150$ & \\
\hline 23 & $\mathrm{~L}$ & Valtellina, Lombardy, northern Italy & $\mathrm{S}$ & $I=44.67 \times D^{-0.78}$ & $1<D<1000$ & \\
\hline 24 & $\mathrm{~L}$ & Rho Basin, Piedmont, NW Italy & $\mathrm{D}$ & $I=9.52 \times D^{-0.50}$ & $1<D<24$ & \\
\hline 25 & $\mathrm{~L}$ & Rho Basin, Piedmont, NW Italy & $\mathrm{D}$ & $I=11.70 \times D^{-0.48}$ & $1<D<24$ & \\
\hline 26 & $\mathrm{~L}$ & Perilleux Basin, Piedmont, NW Italy & $\mathrm{D}$ & $I=11.00 \times D^{-0.45}$ & $1<D<24$ & \\
\hline 27 & $\mathrm{~L}$ & Perilleux Basin, Piedmont, NW Italy & $\mathrm{D}$ & $I=10.67 \times D^{-0.50}$ & $1<D<24$ & \\
\hline 28 & $\mathrm{~L}$ & Champeyron Basin, Piedmont, NW Italy & $\mathrm{D}$ & $I=12.65 \times D^{-0.53}$ & $1<D<24$ & \\
\hline 29 & $\mathrm{~L}$ & Champeyron Basin, Piedmont, NW Italy & $\mathrm{D}$ & $I=18.68 \times D^{-0.57}$ & $1<D<24$ & \\
\hline 30 & $\mathrm{~L}$ & Moscardo Torrent, NE Alps, Italy & A & $I=15.00 \times D^{-0.70}$ & $1<D<30$ & \\
\hline 31 & $\mathrm{~L}$ & Valzangona, northern Apennines, Italy & A & $I=18.83 \times D^{-0.59}$ & $24<D<3360$ & \\
\hline 32 & $\mathrm{~L}$ & Apuane Alps, Tuscany, central Italy & $\mathrm{Sh}$ & $I=26.87 \times D^{-0.64}$ & $0.1<D<35$ & \\
\hline 33 & $\mathrm{~L}$ & Apuane Alps, Tuscany, central Italy & $\mathrm{Sh}$ & $I=85.58 \times D^{-0.78}$ & $0.1<D<35$ & \\
\hline 34 & $\mathrm{~L}$ & Apuane Alps, Tuscany, central Italy & $\mathrm{Sh}$ & $I=38.36 \times D^{-0.74}$ & $0.1<D \leq 12$ & \\
\hline 35 & $\mathrm{~L}$ & Apuane Alps, Tuscany, central Italy & $\mathrm{Sh}$ & $I=76.20 \times D^{-0.69}$ & $0.1<D \leq 12$ & \\
\hline
\end{tabular}

$\mathrm{T}_{5}$, red line) methods. Rainfall events that have resulted in landslides in the Abruzzo Region considered for the determination of the thresholds are in the range of duration $1 \mathrm{~h}<D<600 \mathrm{~h}$, and in the range of mean intensity $0.3 \mathrm{~mm} \mathrm{hr}^{-1}<I<50 \mathrm{~mm} \mathrm{hr}^{-1}$, with the majority of the events in the range $0.5 \mathrm{~mm} \mathrm{hr}^{-1}<I<2.5 \mathrm{~mm} \mathrm{hr}^{-1}$.
Examination of Fig. $3 \mathrm{~b}$ and Table 1 indicates that the three regional thresholds are similar. For a rainfall duration $D$ of one hour, the rainfall mean intensity $I$ is $4.2 \mathrm{~mm} \mathrm{hr}^{-1}$ for $\mathrm{T}_{1}, 5.5 \mathrm{~mm} \mathrm{hr}^{-1}$ for $\mathrm{T}_{\mathrm{B}}$, and $5.9 \mathrm{~mm} \mathrm{hr}^{-1}$ for $\mathrm{T}_{5}$. For a rainfall duration $D$ of $24 \mathrm{~h}$ (one day), $I$ is $0.7 \mathrm{~mm} \mathrm{hr}^{-1}$ for $\mathrm{T}_{1}$, $0.8 \mathrm{~mm} \mathrm{hr}^{-1}$ for $\mathrm{T}_{\mathrm{B}}$, and $1.0 \mathrm{~mm} \mathrm{hr}^{-1}$ for $\mathrm{T}_{5}$. In the Abruzzo Region, the $\mathrm{T}_{1}$ threshold is the most conservative, for the 

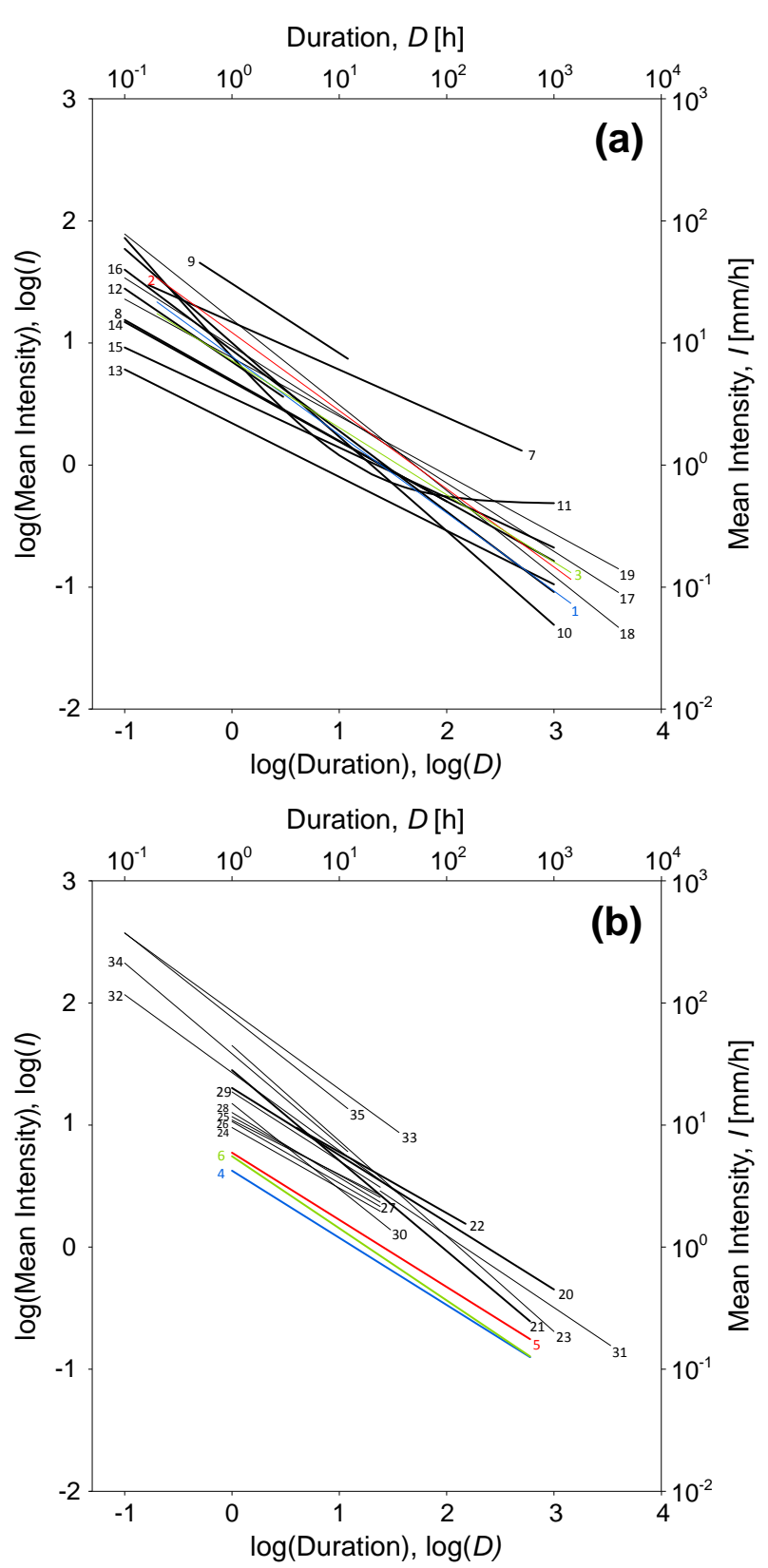

Fig. 4. Comparison of rainfall thresholds for possible landslide occurrence in Italy. New national (a) and regional (b) thresholds are in colour: green, $\mathrm{T}_{\mathrm{B}}$ Bayesian threshold; light blue, $\mathrm{T}_{1} 1 \%$ Frequentist threshold; red, $\mathrm{T}_{5} 5 \%$ Frequentist threshold. (a) Global (thick line) and national (thin line) thresholds for Italy; source: $1-3$, this work; 7, Caine (1980); 8, Innes (1983); 9, Jibson (1989); 10, Clarizia et al. (1996); 11, Crosta and Frattini (2001); 12, Cannon and Gartner (2005); 13-16, Guzzetti et al. (2008); 17-19, Guzzetti et al. (2007). (b) Regional (thick line) and local (thin line) thresholds, and new thresholds for the Abruzzo Region (coloured). Source 4-6, this work; 20, Ceriani et al. (1994) in Bacchini and Zannoni (2003); 21, Calcaterra et al. (2000); 22, Aleotti (2004); 23, Cancelli and Nova (1985); 24-29, Bolley and Olliaro (1999); 30, Marchi et al. (2002); 31, Floris et al. (2004); 32-35, Giannecchini (2005). Numbers refer to \# in Table 1. entire range of considered durations, $0.5 \mathrm{~h}<D<600 \mathrm{~h}$. Also, the $\mathrm{T}_{\mathrm{B}}$ threshold is slightly steeper $(\beta=0.59)$ than the $\mathrm{T}_{1}$ and $\mathrm{T}_{5}$ thresholds $(\beta=0.55)$. This is opposite to what was found for the national thresholds. The difference may be due to the reduced size of the data set (only 77 data points), or it may reflect different physiographical or meteorological conditions that control landslide occurrence in the Abruzzo Region. The reduced number of empirical data does not allow for further considerations.

\section{Discussion}

The new sets of rainfall thresholds for the possible occurrence or rainfall induced landslides in Italy (Fig. 3a) and in the Abruzzo Region (Fig. 3b) can be compared to each others, and to similar (i.e., ID) global, national, regional, and local thresholds proposed for Italy (for a review, see Guzzetti et al., 2007, 2008). Comparison of the new national (Fig. 3a) and regional (Fig. 3b) thresholds reveals that the regional thresholds for the Abruzzo Region are systematically lower than the corresponding national thresholds for Italy. This was unexpected, as regional (and even more local) thresholds are usually higher than national (or global) thresholds (Guzzetti et al., 2007).

Based on the regional thresholds $T_{1}$ and $T_{B}$ established for the Abruzzo Region, for rainfall duration of $12 \mathrm{~h}$, the rainfall mean intensity $I$ required to generate slope failures (in the Abruzzo Region) is about $70 \%\left(\sim 1.1 \mathrm{~mm} \mathrm{hr}^{-1}\right.$ for $\mathrm{T}_{1}$ and $\sim 1.3 \mathrm{~mm} \mathrm{hr}^{-1}$ for $\mathrm{T}_{\mathrm{B}}$ ) the mean intensity required to generate landslides in Italy $\left(\sim 1.6 \mathrm{~mm} \mathrm{hr}^{-1}\right.$ for $\mathrm{T}_{1}$ and $\sim 1.8 \mathrm{~mm} \mathrm{hr}^{-1}$ for $\mathrm{T}_{\mathrm{B}}$ ). We attribute the result to the different types of rainfall events listed in the national catalogue and in the subset for the Abruzzo Region. The vast majority of the 753 rainfall events listed in the national catalogue were obtained from the scientific and technical literature. This source of information privileges severe rainfall events that have resulted in multiple or abundant landslides. These events are characterized usually by large amounts of cumulated (total) rainfall, and correspondingly higher mean intensity values. Conversely, the subset of 77 rainfall events in the Abruzzo Region was obtained primarily from articles found in local newspapers, which reported a number of small (i.e., not particularly damaging), individual landslides triggered by minor rainfall events characterized by low to moderate cumulated rainfall, and a reduced rainfall mean intensity. Although the 77 events in the Abruzzo Region are included in the national catalogue, their proportion $(10.2 \%)$ is insufficient to condition (i.e., lower) the national thresholds significantly, particularly in the case of the Frequentist thresholds.

Figure 4 portrays 35 ID thresholds for the possible initiation of landslides in Italy defined in the literature, including 10 global thresholds (7-16), 3 national (17-19), 3 regional (20-22), and 13 local (23-35) thresholds. In the two plots, the threshold curves are classified as global (G) or national (N) (Fig. 4a), and as regional (R) or local (L) (Fig. 4b) 
thresholds, depending on the extent of the area for which they were defined. The plots also show the three new national thresholds for Italy (1-3, Fig. 4a), and three new regional thresholds for the Abruzzo Region (4-6, Fig. 4b) proposed in this work. Table 1 lists information for all the thresholds shown in Fig. 4, including the extent and the name of the area for which the thresholds were defined, the main landslide type, and the equation and the range of validity for the thresholds. For the new thresholds, the uncertainty associated with the intercept $\alpha$ and the slope $\beta$ of the power law threshold curve are also given.

Inspection of Fig. 4a and Table 1 reveals that the new national thresholds (1-3) are in the range of rainfall mean intensity defined by other global and national thresholds. Notably, the new national thresholds are similar to the thresholds proposed by Guzzetti et al. (2007) for central and southern Europe (CADSES area). Further inspection of Fig. 4b and Table 1 indicates that the new regional thresholds (4-6) are lower to significantly lower than other regional and local thresholds proposed for areas in Italy. In particular, our new regional thresholds for the Abruzzo Region are lower than the regional thresholds proposed e.g. by Aleotti (2004) for the Piedmont Region, by Ceriani et al. (1994) for the Lombardy Region, northern Italy, and by Calcaterra et al. (2000) for the Campania Region, southern Italy. Although we cannot exclude that this result is partially due to diverse physiographical (e.g., meteorological, morphological, lithological) and land cover conditions in the different Regions, we hypothesize that the result depends primarily on the type of information used to define the thresholds by the different authors.

The new sets of rainfall thresholds for the possible occurrence of landslides in Italy (Fig. 3a) and in the Abruzzo Region (Fig. 3b) were obtained from the empirical rainfall data using two different statistical techniques. The two independent (Bayesian and Frequentist) techniques resulted in similar thresholds, for the national and the regional data sets. We take this as an indication of the consistency of the thresholds. The new sets of thresholds were obtained adopting rigorous criteria that have resulted in objective (i.e., reproducible) thresholds. In addition, levels of uncertainty were associated with the thresholds. This is an improvement over existing methods to determine empirical rainfall thresholds based on visual interpolation of empirical data points.

The Frequentist and the Bayesian methods have conceptual and practical advantages and weaknesses. Given the reduced number of empirical data sets available to test the two methods, and the limited experience in the application of the methods, it is difficult to decide which method performs best, and under what set of conditions. However, general and specific considerations can be made.

In the Frequentist method, the intercept $\alpha$ and the slope $\beta$ of the power law curve chosen to represent the rainfall threshold are estimated through linear fitting of the empirical rainfall data points, based on a least-square minimiza- tion criterion. As an alternative, $\alpha$ and $\beta$ can be estimated through maximum likelihood (White et al., 2008). In both cases, the quality of the result depends on the abundance and the distribution of the empirical data points. In general, the Frequentist method will provide better results when applied to a large data set covering consistently the range of rainfall duration $D$ and mean intensity $I$, than when used on a small data set covering unevenly the same duration and mean intensity ranges. In the estimation of the intercept $\alpha$ and the slope $\beta$ of the power law threshold curve, the Bayesian method is more sensitive to rainfall data points near the threshold, and less sensitive to data points distant from the threshold. This makes the Bayesian method more sensitive to the (relative) position of a few data points, and best suited to examine small data sets.

Visual inspection of the empirical rainfall data, and of the corresponding national (Fig. 3a) and regional (Fig. 3b) thresholds, suggests that the Frequentist method was more effective in determining the minimum thresholds for the larger (753 data points) national data set, and that the $\mathrm{T}_{1}$ Frequentist threshold represented the minimum-ID rainfall conditions required to initiate landslides in Italy better than the $\mathrm{T}_{\mathrm{B}}$ Bayesian threshold. Conversely, the Bayesian threshold seems to better represent the minimum rainfall conditions that can result in landslides in the Abruzzo Region (Fig. 3b). This confirms the general consideration that the Frequentist method is more suited to treat large data sets, and the Bayesian method is more appropriate for small data sets.

The Bayesian method results in a single minimum-ID threshold, whereas the Frequentist approach allows for the definition of multiple thresholds, depending on different exceedance levels. The latter characteristic is useful when deciding a threshold for an operational landslide warning system (Keefer, 1987; Aleotti, 2004; Hong et al., 2006; Guzzetti et al., 2008). Assuming an empirical data set of rainfall events which have resulted in landslides is representative for the area where the threshold has to be determined, different exceedance levels correspond to a different number of acceptable false alarms i.e., rainfall conditions $(D, I)$ lower than the threshold that result in slope failures (false negatives, or type II errors, Allchin, 2001).

Definition of multiple thresholds decided on different exceedance probability levels allows for the design of probabilistic schemes (or charts) for predicting possible landslide occurrence, based on rainfall measurements or forecasts. Figure 5 portrays an example of such scheme, designed for a prototype national landslide warning system in Italy (Brunetti et al., 2009).

The scheme (Fig. 5b) is based on four Frequentist thresholds, namely: (i) the $\mathrm{T}_{0.005}$ threshold, that corresponds to an exceedance probability $p=5 \times 10^{-5}, 0.005 \%$ of the area under the Gaussian fit in Fig. 5a is below the threshold, (ii) the $\mathrm{T}_{0.5}$ threshold, that corresponds to an exceedance probability $p=0.005$, (iii) the $\mathrm{T}_{1.5}$ threshold, with an exceedance probability $p=0.015$, and a $\mathrm{T}_{5}$ threshold, that corresponds to an 
(a)

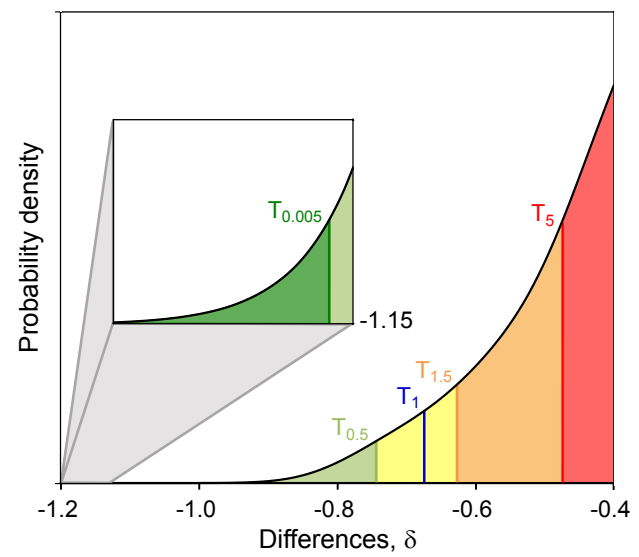

(b)

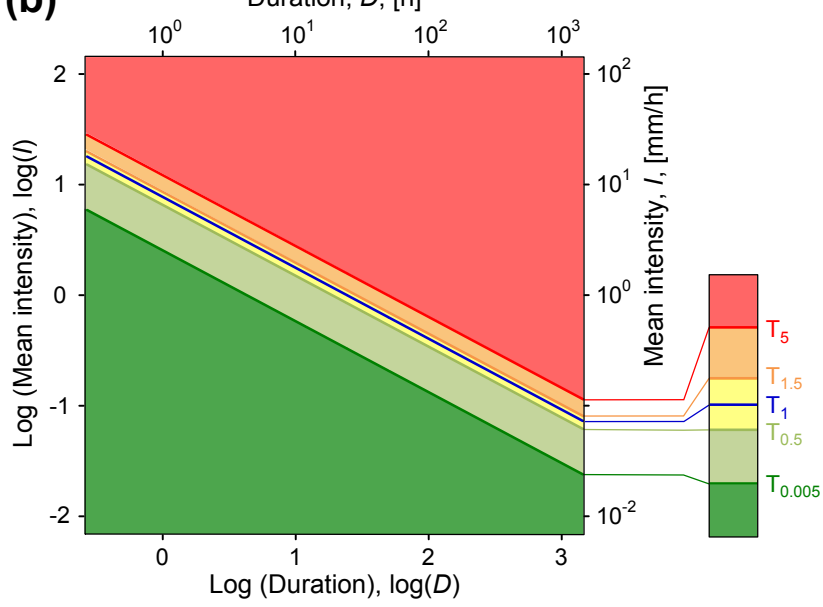

Fig. 5. Critical rainfall conditions defined by thresholds having different exceedance probability shown (a) in the Gaussian curve (see Fig. 2), and (b) in the $D-I$ plane. Legend: dark green, rainfall condition "well below the threshold"; light green, "below the threshold"; yellow, "on the threshold"; orange, "above the threshold"; red, "well above the threshold".

exceedance probability $p=0.05,5.0 \%$ of the area under the Gaussian fit in Fig. 5a is below this threshold. Note that the lowest $\mathrm{T}_{0.005}$ threshold corresponds to the four standard deviations $(4 \sigma)$ exceedance level $\left(p=5 \times 10^{-5}\right)$ from the $\mathrm{T}_{50}$ threshold, which is the mean value of the Gaussian curve.

In the scheme, the four thresholds separate five ID fields, shown by different colours in Fig. 5b. The resulting chart can be used to forecast (predict) possible landslide occurrence. For any given rainfall duration $D$, when the (measured or predicted) rainfall mean intensity $I$ is lower than the lowest $\mathrm{T}_{0.005}$ threshold, the rainfall condition is "well below" the $\mathrm{T}_{1}$ threshold (dark green area in Fig. 5b). In this area of the chart, landslides are typically not expected, with a chance of false negatives (rainfall events in the dark green area that result in landslides) of $0.005 \%$ (an odd of $1 / 20000$ ). Similarly, when the rainfall mean intensity $I$ is equal to, or larger than, the upper $\mathrm{T}_{5}$ threshold, the rainfall condition is "well above" the $\mathrm{T}_{1}$ threshold (red area in Fig. 5b). In this area, landslides are typically expected, with a chance of false negatives (rainfall events below the red area that result in landslides) of $5.0 \%$ or less (an odd of $1 / 20$ or smaller). For events with a mean intensity $I$ in the range defined by the $\mathrm{T}_{0.5}$ and the $\mathrm{T}_{1.5}$ thresholds (and containing the $\mathrm{T}_{1}$ threshold), the rainfall condition is considered "on the $\left(\mathrm{T}_{1}\right)$ threshold" (yellow area in Fig. 5b). In this portion of the chart, landslides can be expected depending on local susceptibility conditions, with a chance of false negatives (rainfall events below the yellow area that result in landslides) of $0.5 \%$ (an odd of $1 / 200$ or smaller). In the chart, the orange and the light green sections represent intermediate conditions, classified as "above" the $\mathrm{T}_{1}$ threshold and "below" the $\mathrm{T}_{1}$ threshold, respectively.

Different charts can be designed based on different reference thresholds, different accepted number of false negatives, and a different number of prediction classes.

\section{Conclusions}

Using a variety of sources of information, we have compiled a new catalogue that lists 753 rainfall events that have resulted in landslides in Italy. The catalogue represents the single largest collection of information on rainfall-induced landslides in Italy. Construction of the catalogue revealed the importance - and the difficulty - of obtaining accurate and dependable rainfall and landslide information for the definition of reliable thresholds. In this context, availability of the national database of sub-hourly rainfall measurements was instrumental for the proper selection and characterization of the rainfall and landslide events.

We have exploited the catalogue to determine new rainfall intensity-duration (ID) thresholds for the possible occurrence of landslides in Italy, and in the Abruzzo Region, central Italy. To establish the thresholds, we experimented with two independent statistical approaches, a Bayesian approach (Guzzetti et al., 2007) and a new Frequentist approach. Our experiment outlined the importance - and the advantage - of adopting rigorous criteria for the definition of the thresholds. When applied to the national and the regional data sets, the two statistical approaches resulted in comparable outcomes, and proved complementary. Bayesian inference proved more dependable when dealing with small data sets, and the Frequentist approach was best when applied to a large data set.

Comparison of the thresholds revealed that the new regional thresholds for the Abruzzo Region are lower than the new national thresholds for Italy, and lower than regional thresholds proposed for Piedmont (Aleotti, 2004), Lombardy (Ceriani et al., 1994), and the Campania Region (Calcaterra et al., 2000). This unexpected result is relevant because it shows that landslides in Italy can be triggered by less severe 
rainfall conditions that previously recognized. It is an important information to forecast landslide occurrence and to ascertain landslide hazards.

Allowing for the definition of multiple thresholds based on different exceedance probability levels, the Frequentist method was functional to the design of a probabilistic scheme for the prediction of the possible landslide occurrence. Such scheme, or other similar schemes, can be implemented in landslide warning systems operating at different geographical scales, based on rainfall measurements or forecasts.

Acknowledgements. Work financially supported by the Italian national Department for Civil Protection (DPC) that also provided the national rainfall database for the period 2002-2009. MTB, SP and MR supported by DPC grants. We would like to thank Gabriele Tonelli for his work on the rainfall database.

Edited by: T. Glade

Reviewed by: K.-T. Chang and S. Bai

\section{References}

Abramowitz, M. and Stegun, I. A. (Eds.): Handbook of Mathematical Functions with Formulas, Graphs, and Mathematical Tables, 10th edn., National Bureau of Standards, John Wiley and Sons, 1972.

Aleotti, P.: A warning system for rainfall-induced shallow failures, Eng. Geol., 73, 247-265, 2004.

Allchin, D.: Error Types, Perspectives on Science, 9(1), 38-58, 2001.

Bacchini, M. and Zannoni, A.: Relations between rainfall and triggering of debris-flow: case study of Cancia (Dolomites, Northeastern Italy), Nat. Hazards Earth Syst. Sci., 3, 71-79, 2003, http://www.nat-hazards-earth-syst-sci.net/3/71/2003/.

Bolley, S. and Oliaro, P.: Analisi dei debris flows in alcuni bacini campione dell'Alta Val Susa, Geoingegneria Ambientale e Mineraria, March, 69-74, 1999 (in Italian).

Brunetti, M. T., Peruccacci, S., Rossi, M., Guzzetti, F., Reichenbach, P., Ardizzone, F., Cardinali, M., Mondini, A., Salvati, P., Tonelli, G., Valigi, D., and Luciani, S.: A prototype system to forecast rainfall induced landslides in Italy, in: Proceedings of the 1st Italian Workshop on Landslides, edited by: Picarelli, L., Tommasi, P., Urciuoli, G., and Versace, P., Rainfall-Induced Landslides: mechanisms, monitoring techniques and nowcasting models for early warning systems, Naples, 1, 157-161, 2009.

Caine, N.: The rainfall intensity-duration control of shallow landslides and debris flow, Geogr. Ann. A, 62, 23-27, 1980.

Calcaterra, D., Parise, M., Palma, B., and Pelella, L.: The influence of meteoric events in triggering shallow landslides in pyroclastic deposits of Campania, Italy, in: Proceedings of the 8th International Symposium on Landslides, edited by: Bromhead, E., Dixon, N., and Ibsen, M. L., A. A. Balkema, Cardiff, 1, 209-214, 2000.

Cancelli, A. and Nova, R.: Landslides in soil debris cover triggered by rainstorms in Valtellina (central Alps - Italy), in: Proceedings of the 4th International Conference and Field Workshop on Landslides, The Japan Geological Society, Tokyo, 267-272, 1985.
Cardinali, M., Ardizzone, F., Galli, M., Guzzetti, F., and Reichenbach, P.: Landslides triggered by rapid snow melting, the December 1996-January 1997 event in Central Italy, in: Proceedings of the 1st EGS Plinius Conference on Mediterranean Storms, Maratea, 14-16 October 1999, edited by: Claps, P. and Siccardi, F., Editoriale Bios, Cosenza, 439-448, 2000.

Cannon, S. H. and Gartner, J. E.: Wildfire-related debris flow from a hazards perspective, in: Debris flow hazards and related phenomena, edited by: Jakob, M. and Hungr. O., Springer, Berlin, 363-385, 2005.

Ceriani, M., Lauzi, S., and Padovan, N.: Rainfall thresholds triggering debris-flows in the alpine area of Lombardia Region, central Alps - Italy, Proc. Man and Mountain, I Conv. Intern. per la Protezione e lo Sviluppo dell'ambiente montano, Ponte di Legno (BS), 123-139, 1994.

Clarizia, M., Gullà, G., and Sorbino, G.: Sui meccanismi di innesco dei soil slip, in: Proceedings of International Conference on Prevention of Hydro-geological Hazards: The Role of Scientific Research Alba, Italy, 1, 585-597, 5-7 November 1996.

Corominas, J.: Landslides and climate. Keynote lecture, in: Proceedings of the 8th International Symposium on Landslides, edited by: Bromhead, E., Dixon, N., and Ibsen, M. L., A. A. Balkema, Cardiff, 4, 1-33, 2000.

Crosta, G. B. and Frattini, P.: Distributed modelling of shallow landslides triggered by intense rainfall, Nat. Hazards Earth Syst. Sci., 3, 81-93, 2003, http://www.nat-hazards-earth-syst-sci.net/3/81/2003/.

Crosta, G. B. and Frattini, P.: Rainfall thresholds for triggering soil slips and debris flow, in: Proceedings of the 2nd EGS Plinius Conference on Mediterranean Storms, edited by: Mugnai, A., Guzzetti, F., and Roth, G., Siena, Italy, 463-487, 16-18 October 2001.

Cruden, D. M. and Varnes, D. J.: Landslide types and processes, in: Landslides, Investigation and Mitigation, Transportation Research Board, edited by: Turner, A. K. and Schuster, R. L., Special Report 247, Washington, DC, 36-75, 1996.

Floris, M., Mari, M., Romeo, R. W., and Gori, U.: Modelling of landslide-triggering factors - A case study in the northern Apennines, Italy, Lect. Notes Earth Sci. 104, 745-753, 2004.

Giannecchini, R.: Rainfall triggering soil slips in the southern Apuan Alps (Tuscany, Italy), Adv. Geosci., 2, 21-24, 2005, http://www.adv-geosci.net/2/21/2005/.

Guzzetti, F.: Landslide fatalities and evaluation of landslide risk in Italy, Eng. Geol., 58, 89-107, 2000.

Guzzetti, F., Cardinali, M., and Reichenbach, P.: The AVI Project: A bibliographical and archive inventory of landslides and floods in Italy, Environ. Manage., 18, 623-633, 1994.

Guzzetti, F., Peruccacci, S., Rossi, M., and Stark, C. P.: Rainfall thresholds for the initiation of landslides in central and southern Europe, Meteorol. Atmos. Phys., 98, 239-267, 2007.

Guzzetti, F., Peruccacci, S., Rossi, M., and Stark, C. P.: The rainfall intensity-duration control of shallow landslides and debris flows: an update, Landslides, 5(1), 3-17, 2008.

Guzzetti, F., Salvati, P., and Stark, C. P.: Evaluation of risk to the population posed by natural hazards in Italy, in: Landslide risk management, edited by: Hungr, O., Fell, R., Couture, R., and Eberhardt, E., Taylor \& Francis Group, London, 381-389, $2005 a$. 
Guzzetti, F., Stark, C. P., and Salvati, P.: Evaluation of flood and landslide risk to the population of Italy, Environ. Manage., 36(1), 15-36, 2005b.

Guzzetti, F. and Tonelli, G.: Information system on hydrological and geomorphological catastrophes in Italy (SICI): a tool for managing landslide and flood hazards, Nat. Hazards Earth Syst. Sci., 4, 213-232, 2004, http://www.nat-hazards-earth-syst-sci.net/4/213/2004/.

Hong, Y., Adler, R., and Huffman, G.: Evaluation of the potential of NASA multi-satellite precipitation analysis in global landslide hazard assessment, Geophys. Res. Lett., 33, L22402, doi:10.1029/2006GL028010, 2006.

Innes, J. L.: Debris flows, Prog. Phys. Geogr., 7, 469-501, 1983.

Iverson, R. M.: Landslide triggering by rain infiltration, Water Resour. Res., 36(7), 1897-1910, 2000.

Jakob, M. and Weatherly, H.: A hydroclimatic threshold for landslide initiation on the North Shore Mountains of Vancouver, British Columbia, Geomorphology, 54, 137-156, 2003.

Jibson, R. W.: Debris flow in southern Porto Rico, Geological Society of America, 236, 29-55, 1989.

Keefer, D. K., Wilson, R. C., Mark, R. K., Brabb, E. E., Brown III, W. M., Ellen, S. D., Harp, E. L., Wieczorek, G. F., Alger, C. S., and Zatkin, R. S.: Real-time landslide warning during heavy rainfall, Science, 238, 921-925, 1987.

Köppen, V. P.: Das geographische System der Klimate, in: Handbuch der Klimatologie, edited by: Köppen, W. and Geiger, R., Berlin, Gebrüder Bornträger, Band 5, Teil C, 44 pp., 1936 (in German).

Luino, F.: Sequence of instability processes triggered by heavy rainfall in the northern Italy, Geomorphology, 66(1-4), 13-39, 2005.

Lunn, D. J., Thomas, A., Best, N., and Spiegelhalter, D.: WinBUGS - a Bayesian modelling framework: concepts, structure, and extensibility, Stat. Comput., 10, 325-337, 2000.

Marchi, L., Arattano, M., and Deganutti, A. M.: Ten years of debrisflow monitoring in the Moscardo Torrent (Italian Alps), Geomorphology, 46, 1-17, 2002.

Montgomery, D. R. and Dietrich, W. E.: A physically based model for the topographic control of shallow landsliding, Water Resour. Res., 30(4), 1153-1171, 1994.

Reichenbach, P., Cardinali, M., De Vita, P., and Guzzetti, F.: Regional hydrological thresholds for landslides and floods in the Tiber River Basin (central Italy), Environm. Geol., 35(2-3), 146159, 1998.
Regione Piemonte: Eventi Alluvionali in Piemonte: 2-6 novembre 1994, 8 luglio 1996, 7-10 ottobre 1996 (in Italian), Direzione Servizi Tecnici di Prevenzione, Torino, 415 pp., 1998.

Salvati, P., Guzzetti, F., Reichenbach, P., Cardinali, M., and Stark, C. P.: Map of landslides and floods with human consequences in Italy, Pubblication CNR GNDCI n. 2822, Scale 1:1 200000 , 2003.

Salvati, P., Bianchi, C., Rossi, M., and Guzzetti, F.: Societal landslide and flood risk in Italy, Nat. Haz. Earth Syst. Sci., in press, 2010.

Servizio Geologico, Sismico dei Suoli: I numeri delle frane, Regione Emilia-Romagna Publisher, Bologna, 94 pp., 1999 (in Italian).

Scott, D. W.: Multivariate Density Estimation, in: Theory, Practice and Visualization, Wiley, New York, 1992.

Silverman, B. W.: Density Estimation, Chapman and Hall, London, 1986.

Trewartha, G. T.: An introduction to climate, 4th edn., McGrawHill, New York, 408 pp., 1968.

Trigila, A. (Ed.): Rapporto sulle frane in Italia. Il Progetto IFFI Metodologia, risultati e rapporti regionali, APAT, Roma, 681 pp., 2007 (in Italian).

Venables, W. N. and Ripley, B. D.: Modern Applied Statistics with S, Springer, New York, 2002.

Wieczorek, G. F. and Glade, T.: Climatic factors influencing occurrence of debris flows, in: Debris flow hazards and related phenomena, edited by: Jakob, M. and Hungr, O., Berlin Heidelberg, Springer, 325-362, 2005.

Wilson, R. C. and Jayko, A. S.: Preliminary maps showing rainfall thresholds for debris-flow activity, San Francisco Bay Region, California, US Geological Survey Open-File Report 97-745 F, 1997.

Wilson, R. C. and Wieczorek, G. F.: Rainfall thresholds for the initiation of debris flow at La Honda, California, Environ. Eng. Geosci., 1(1), 11-27, 1995.

White, E. P., Enquist, B. J., and Green, J. L.: On estimating the exponent of power-law frequency distributions, Ecology, 89(4), 905-912, doi:10.1890/07-1288.1, 2008.

Wu, W. and Sidle, R. C.: A distributed slope stability model for steep forested basins, Water Resour. Res., 31, 2097-2110, 1995. 